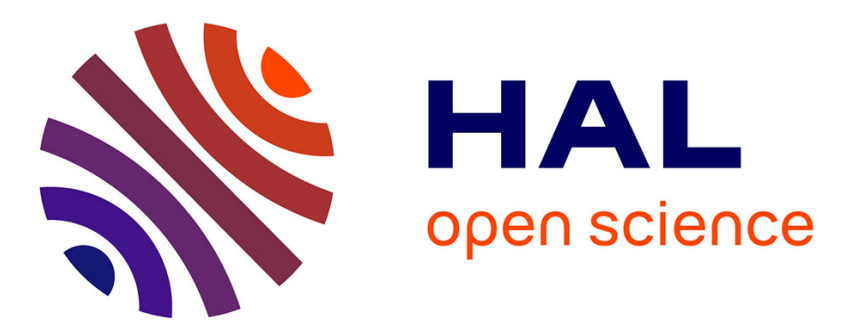

\title{
Modeling of Processes and Decisions in Healthcare - State of the Art and Research Directions
}

\author{
Eystein Mathisen, John Krogstie
}

\section{To cite this version:}

Eystein Mathisen, John Krogstie. Modeling of Processes and Decisions in Healthcare - State of the Art and Research Directions. 5th Working Conference on the Practice of Enterprise Modeling (PoEM), Nov 2012, Rostock, Germany. pp.101-116, 10.1007/978-3-642-34549-4_8 . hal-01484404

\author{
HAL Id: hal-01484404 \\ https://hal.inria.fr/hal-01484404
}

Submitted on 7 Mar 2017

HAL is a multi-disciplinary open access archive for the deposit and dissemination of scientific research documents, whether they are published or not. The documents may come from teaching and research institutions in France or abroad, or from public or private research centers.
L'archive ouverte pluridisciplinaire HAL, est destinée au dépôt et à la diffusion de documents scientifiques de niveau recherche, publiés ou non, émanant des établissements d'enseignement et de recherche français ou étrangers, des laboratoires publics ou privés. 


\title{
Modeling of Processes and Decisions in Healthcare - State of the Art and Research Directions
}

\author{
Eystein Mathisen $^{1,2}$ and John Krogstie ${ }^{2}$ \\ ${ }^{1}$ Bodø Graduate School of Business, University of Nordland, 8072 Bodø, Norway \\ eystein.mathisen@uin.no \\ ${ }^{2}$ Department of Computer and Information Science, Norwegian University of Science and \\ Technology (NTNU), 7491 Trondheim, Norway \\ krogstie@idi.ntnu.no
}

\begin{abstract}
In order to be able to deliver efficient and effective decision support technologies within healthcare, it is important to be able to understand and describe decision making in medical diagnosis, treatment and administrative processes. This paper outlines how information can be synthesized, interpreted and used during decision making in dynamic healthcare environments. We intend to develop a set of modeling constructs that describe the decision requirements forming the basis for adequate situation awareness in clinical processes. We propose that a separate decision perspective will 1) enhance the shared understanding of the decision context among clinical staff, and 2) provide a better understanding of how we can design information system support for complex cognitive tasks in dynamic work environments.
\end{abstract}

\section{Introduction}

The clinical and administrative processes in today's healthcare environments are becoming increasingly complex and intertwined and the provision of clinical care involves a complex series of physical and cognitive activities. A multitude of stakeholders and healthcare providers with the need for rapid decision-making, communication and coordination, together with the steadily growing amount of medical information, all contribute to the view of healthcare as a complex cognitive work domain. The healthcare environments can also be characterized as a very dynamic work environment, in which clinicians rapidly switch between work activities and tasks. The process is partially planned, but at the same time driven by events and interrupts [1, 2].

To be able to cope with the dynamism and complexities in their environments, many organizations have been forced to restructure their operations and integrate complex business processes across functional units and across organizational boundaries [3]. This has in many cases led to the adoption of process-oriented approaches and enterprise modeling to the management of organizational operations. Process modeling is used within organizations as a method to increase the focus on and knowledge of organizational processes, and function as a key instrument to organize activities and to improve the understanding of their interrelationships[4]. Today, there 
is a large number of modeling languages with associated notations as we will discuss in more detail in section 3 .

Recent work within the healthcare domain has been studying how one can best adopt process orientation and process oriented information systems in order to provide effective and efficient solutions for healthcare processes, exemplified by the concepts of patient care, clinical pathways or patient trajectories [5]. The adoption of process-orientation in the healthcare sector is addressing the quality of the outcomes of care processes (e.g. clinical outcomes and patient satisfaction) as well as improvements in operational efficiency [6]).

In this context, it is important to note that research has shown that performance differences between organizations operating in dynamic and complex environments are related to how people decide and act [7]. Hence, the focus of this research relates to how clinical decision-makers adapt to dynamic and complex healthcare environments and how information is synthesized, interpreted and used during decision-making in these contexts. The concept of decision-making is not a well-researched phenomenon in relation to the mapping and modeling of healthcare processes. It is argued here that the complexity of organizational decision making in general (see e.g. [8]) is not reflected in the various modeling languages and methods that are currently available, even though decision making is an inherent and important part of every non-trivial organizational process. Thus, we want to investigate how decision-making expertise can be expressed in enterprise models describing healthcare processes.

The organization of the paper is as follows: Section 2 describes and discusses some of the most prevalent challenges within healthcare. Section 3 presents the theoretical background for the project, with focus on (process) modeling and situation awareness as a prerequisite for decision making, followed by a presentation of decision making theories and process modeling in healthcare. Section 4 gives an overview of the proposed research directions for this area while section 5 provides closing remarks.

\section{Challenges in the Healthcare Domain}

The healthcare domain is a typical risky, complex, uncertain and time-pressured work environment. Healthcare workers experience many interruptions and disruptions during a shift. Resource constraints with regards to medical equipment/facilities and staff availability, qualifications, shift and rank (organizational hierarchy) are commonplace. Clinical decisions made under these circumstances can have severe consequences. Demands for care can vary widely due to the fact that every patient is unique. This uniqueness implies that the patient's condition, diagnosis and the subsequent treatment processes are highly situation-specific. Work is performed on patients whose illnesses and response to medical treatment can be highly unpredictable. Medical care is largely oriented towards cognitive work like planning, problem solving and decision making. In addition the many practical activities that are needed to perform medical care - often including the use of advanced technology - requires cognitive work as well. Thus, the needs of individual patients depend on the synchronization of clinical staff, medical equipment and tools as well as facilities (e.g. operating rooms). The management of procedures for a set of operating rooms or an intensive care unit must be planned and the associated resources and activities require coordination [9]. Planning, problem solving and decision making involves the assessment of resource availability, resource allocation, the projection of future events, and assessment of the 
best courses of action. According to Miller et al. [10], members of a healthcare team must coordinate the acquisition, integration and interpretation of patient and teamrelated information to make appropriate patient care decisions. tions

Clinicians face two types of data processing challenges in decision-making situa-

1. Deciding on medical acts - what to do with the patient.

2. Deciding on coordination acts - which patient to work on next. Knowing what has been going on in the clinical process enables clinicians to adapt their plans and coordinate their work with that of others. In addition to patient data, these decisions are informed by data about what other personnel are doing and which resources (rooms and equipment) are in use.

From the above discussion, we argue that communication and collaboration for informed decision making leading to coordinated action are among the most prevalent challenges that are experienced within healthcare. Lack of adequate team communication and care coordination is often mentioned as the major reasons for the occurrence of adverse events in healthcare [10,11]. According to Morrow et al. [12], errors and adverse events in medical care is related to four broad areas of medical activities: medical device use, medication use, team collaboration, and diagnostic/decision support. In [13], Eisenberg discusses communication and coordination challenges related to healthcare teams and points out the following requirements of these teams:

- A building of shared situational awareness contributing to the development of shared mental models.

- Continuously refreshing and updating the medical team's understanding of the changing context with new information.

- Ensuring that team members adopt a notion of team accountability and enables them to relate their work to the success of the team.

In chapter 3 we will look more closely at the theoretical underpinnings of the proposed research, starting with an overview of perspectives to processes modeling.

\section{Theoretical Background}

\subsection{Perspectives to Process Modeling}

A process is a collection of related, structured tasks that produce a specific service or product to address a certain goal for some actors. Process modeling has been performed in connection with IT and organizational development at least since the 70ties. The archetypical way to look on processes is as a transformation, according to an IPO (input-process-output) approach. Whereas early process modeling languages had this as a basic approach [14], as process modeling have been integrated with other types of conceptual modeling, variants have appeared. Process modeling is usually done in some organizational setting. One can look upon an organization and its information system abstractly to be in a state (the current state, often represented as a descriptive 'as-is' model) that are to be evolved to some future wanted state (often represented as a prescriptive 'to be' model). These states are often modeled, and the state of the organization is perceived (differently) by different persons through these models. Different usage areas of conceptual models are described in $[15,16]$ : 
1. Human sense-making: The descriptive model of the current state can be useful for people to make sense of and learn about the current perceived situation.

2. Communication between people in the organization: Models can have an important role in human communication. Thus, in addition to support the sensemaking process for the individual, descriptive and prescriptive models can act as a common framework supporting communication between people.

3. Computer-assisted analysis: This is used to gain knowledge about the organization through simulation or deduction, often by comparing a model of the current state and a model of a future, potentially better state.

4. Quality assurance, ensuring e.g. that the organization acts according to a certified process developed for instance as part of an ISO-certification process.

5. Model deployment and activation: To integrate the model of the future state in an information system directly. Models can be activated in three ways:

(a) Through people, where the system offers no active support.

(b) Automatically, for instance as an automated workflow system.

(c) Interactively, where the computer and the users co-operate [17].

6. To be a prescriptive model to be used to guide a traditional system development project, without being directly activated.

Modeling languages can be divided into classes according to the core phenomena classes (concepts) that are represented and focused on in the language. This has been called the perspective of the language [15, 18]. Languages in different perspectives might overlap in what they express, but emphasize different concepts as described below. A classic distinction regarding modeling perspectives is between the structural, functional, and behavioral perspective [19]. Through other work, such as [20], [21], F3 [22], NATURE [23], [24, 25] additional perspectives have been identified, including object, goal, actor, communicational, and topological. Thus identified perspectives for conceptual modeling are:

Behavioral perspective: Languages following this perspective go back to the early sixties, with the introduction of Petri-nets [26]. In most languages with a behavioral perspective the main phenomena are 'states' and 'transitions' between 'states'. State transitions are triggered by 'events' [27].

Functional perspective: The main phenomena class in the functional perspective is 'transformation': A transformation is defined as an activity which based on a set of phenomena transforms them to another set of phenomena.

Structural perspective: Approaches within the structural perspective concentrate on describing the static structure of a system. The main construct of such languages is the 'entity'.

Goal and Rule perspective: Goal-oriented modeling focuses on 'goals' and 'rules'. A rule is something which influences the actions of a set of actors. In the early nineties, one started to model so-called rule hierarchies, linking goals and rules at different abstraction levels.

Object-oriented perspective: The basic phenomena of object oriented modeling languages are those found in most object oriented programming languages; 'Objects' with unique id and a local state that can only be manipulated by calling methods of the object. The process of the object is the trace of the events during the existence of the object. A set of objects that share the same definitions of attributes and operations compose an object class.

Communication perspective: The work within this perspective is based on lan- 
guage/action theory from philosophical linguistics [28]. The basic assumption of language/action theory is that persons cooperate within work processes through their conversations and through mutual commitments taken within them.

Actor and role perspective: The main phenomena of modeling languages within this perspective are 'actor' and 'role'. The background for modeling in this perspective comes both from organizational science, work on programming languages, and work on intelligent agents in artificial intelligence.

Topological perspective: This perspective relates to the topological ordering between the different concepts. The best background for conceptualization of these aspects comes from the cartography and CSCW fields, differentiating between space and place [29, 30]. 'Space' describes geometrical arrangements that might structure, constrain, and enable certain forms of movement and interaction; 'place' denotes the ways in which settings acquire recognizable and persistent social meaning through interaction.

\subsection{Situation and context awareness}

A clinician's situation awareness is the key feature for the success of the decision process in medical decision-making. In general, decision makers in complex domains must do more than simply perceive the state of their environment in order to have good situation awareness. They must understand the integrated meaning of what they perceive in light of their goals. Situation awareness incorporates an operator's understanding of the situation as a whole, which forms the basis for decision-making. The integrated picture of the current situation may be matched to prototypical situations in memory, each prototypical situation corresponding to a 'correct' action or decision. Figure 1 shows the model of situation awareness in decision making and action in dynamic environments.

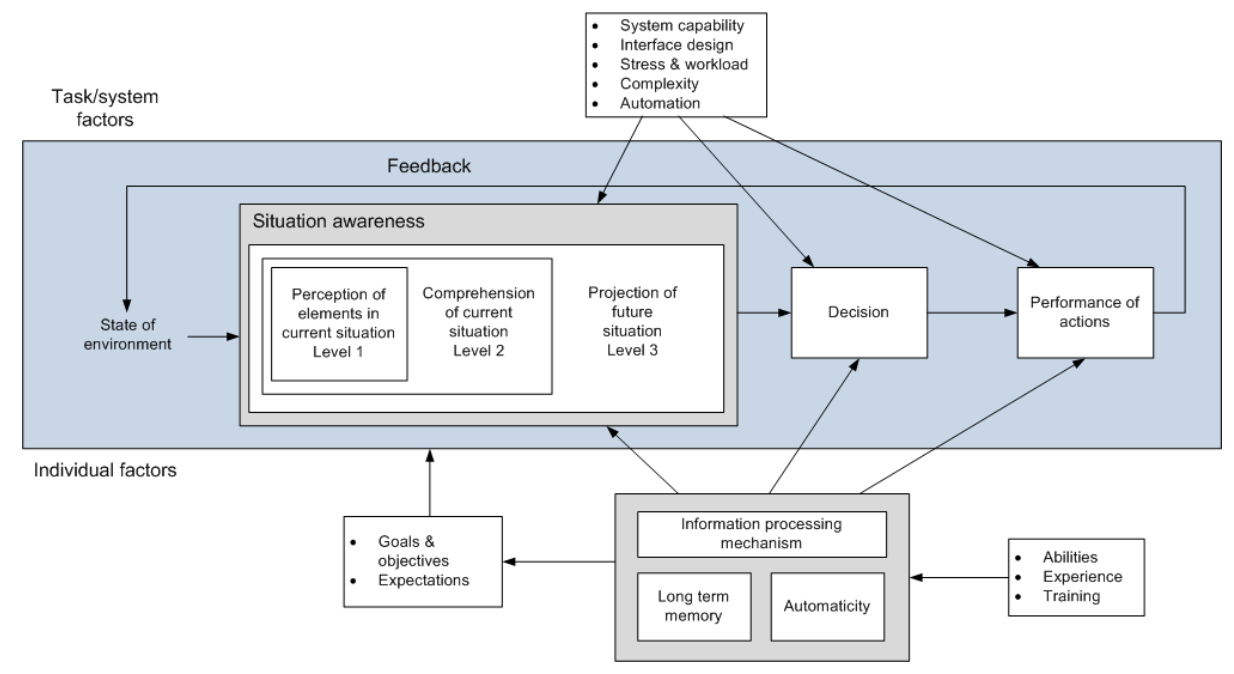

Fig. 1. Situation awareness (from [31], p. 35) 
Situation awareness (SA) is composed of two parts: situation and awareness. Pew [32] defines a 'situation' as "a set of environmental conditions and system states with which the participant is interacting that can be characterized uniquely by a set of information, knowledge and response options." The second part ('awareness') is primarily a cognitive process resulting in awareness. Some definitions put a higher emphasis on this process than the other (situation). For example Endsley [31] defines SA as "the perception of the elements in the environment within a volume of time and space, the comprehension of their meaning, and the projection of their status in the near future". The model in Figure 1 defines three levels of situation awareness. The first level is perception, which refers to the perception of critical cues in the environment. Examples of relevant cues in a clinical setting are patient vital signs, lab results and other team member's current activities. The second level (comprehension) involves an understanding of what the integrated cues mean in relation to the clinician's goals. Here, a physician or a team of medical experts will combine information about past medical history, the current illness(es) and treatments to try to understand the significance of data about the patient's condition. The third level is related to projection, i.e. understanding what will happen with the patient in the future. Using the understanding of the current situation, a clinician or a healthcare team can for instance predict a patient's response to a particular treatment process [33].

According to Endsley and Garland [34], situation awareness is in part formed by the availability of information. This information can be obtained from various sources such as sensory information from the environment, visual/auditory displays, decision aids and support systems, extra- and intra-team communication and team member background knowledge and experience. These information sources will have different levels of reliability giving rise to different levels of confidence in various information sources. Information is primarily aimed at: 1) reducing uncertainty in decision-making and 2) interpretation and sense making in relation to the current situation. Hence, situation awareness is derived from a combination of the environment, the system's displays and other people (team members) as integrated and interpreted by the individual.

In the context of figure 1, mental models help (or block) a person or a team in the process of determining what information is important to attend to, as well as helping to form expectations. Without a 'correct' mental model it would be difficult to obtain satisfactory situation awareness. Processing novel cues without a good mental model, strains the working memory and makes achieving SA much harder and much more prone to error. Mental models provide default information (expected characteristics of elements) that help form higher levels of SA even when needed data is missing or incomplete. Mental models affect the way we handle decisions and actions under uncertainty.

Furthermore, any model of information behavior must indicate something about different stakeholder' information needs and sources. SA is a vital component of the decision making process regardless of the dynamics of the environment within which the decisions are made. SA shapes the mental model of the decision maker and as such influences the perceived choice alternatives and their outcomes.

Although Endsley's work on situation awareness originated within the military and aviation domains, there has been an increasing interest from other areas of research. Within the field of medical decision making research, Patel et al. [35] pointed out the limitations of the classical paradigm of decision research and called for more research within medical decision-making as it occurs in the natural setting. Drawing on the 
concepts of naturalistic decision making and situation awareness, Patel et al. [35] argues that this will enable us to better understand decision processes in general, develop strategies for coping with suboptimal conditions, develop expertise in decisionmaking as well as obtaining a better understanding of how decision-support technologies can successfully mediate decision processes within medical decision making. Examples of research efforts covering situation awareness and decision making within healthcare can be found within anesthesiology [36], primary care [37], surgical decision making [38], critical decision making during health/medical emergency [39] and within evidence-based medical practices in general [40]. Decision making theories will be further elaborated in section 3.3.

Returning to the model of situation awareness presented in figure 1, we notice that there are two factors that constrain practitioners in any complex and dynamic work domain [12]: 1) the task/system factors and 2) the individual/team cognitive factors. Task/system factors focuses on the characteristics of the work environment and the cognitive demands imposed on the practitioners operating in the domain under consideration. According to Vicente [41], this is called the ecological approach and is influenced by the physical and social reality. The cognitive factors, called the cognitivist approach, is concerned with how the mental models, problem solving strategies, decision making and preferences of the practitioners are influenced by the constraints of the work domain.

In the next section we will discuss the main features of decision making, thus covering the cognitivist perspective. In section 4 we also look closer at how enterprise or process models can be used to describe the task environment (i.e. the ecology).

\subsection{Theories of clinical decision making - from decision-analytic to intuitive decision models}

According to the cognitivist perspective, the level of situation awareness obtained is, among other factors, influenced by the practitioner's goals, expectations, mental model (problem understanding), and training. With reference to Endsley's model in fig. 1, we see that decision making is directly influenced by a person's or a team's situation awareness.

The decision making process can be described in more than one way. A classic description of decision making relates the concept to the result of a gradual process the decision process - performed by an actor: the decision maker. The philosopher Churchman puts it this way: The manager is the man who decides among alternative choices. He must decide which choice he believes will lead to a certain desired objective or set of objectives [42]. The decision-making process is described with various action steps and features from one definition to another. Typical steps are the generation of solution alternatives, evaluation of the impact/consequences of options and choice of solutions based on evaluation results and given criteria [43]. Mintzberg et al. [44] have identified three central phases in a general decision making process: 1) identification, 2) development and 3) selection described by a set of supporting 'routines' and the dynamic factors explaining the relationship between the central phases and the supporting routines. The identification phase consists of decision recognition and diagnosis (routines), while the development phase consists of the search and design routines. Finally, the selection phase is a highly iterative process that consists of the screening, evaluation-choice and authorization routines. In a similar manner, Power [45] defines a decision process as consisting of seven stages or steps: 1) defining the 
problem, 2) decide who should decide, 3) collect information, 4) identify and evaluate alternatives, 5) decide, 6) implement and 7) follow-up assessment. In an attempt to improve decision support in requirements engineering, Alenljung and Persson [46] combines Mintzberg's and Power's staged decision process models. Mosier and Fischer [47] discuss decision making in terms of both front-end judgment processes and back-end decision processes. The front-end processes involve handling and evaluating the importance of cues and information, formulating a diagnosis, or assessing the situation. According to Mosier and Fischer, the back-end processes involve retrieving a course of action, weighing different options, or mentally simulating a possible response. This is illustrated in figure 2.

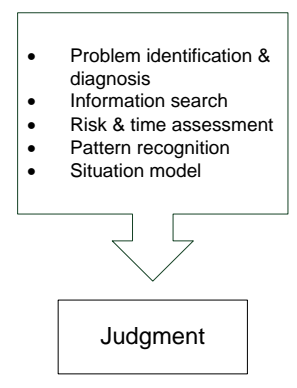

Front-end process

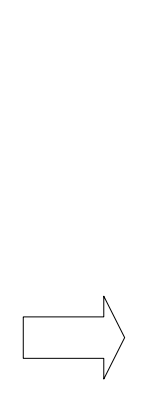

- Response retrieval Adaptation/creation of response

- Mental simulation

- Plan development

Evaluation of alternatives

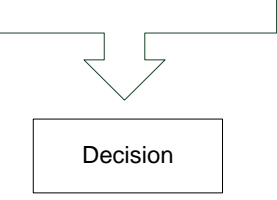

Back-end process

Fig. 2. Components of the decision making process (adapted from [47])

The decision making process is often categorized into rational/analytical and naturalistic/intuitive decision making [48]. This distinction refers to two broad categories of decision-making modes that are not mutually exclusive. This implies that any given decision process in reality consists of analytical as well as intuitive elements. Kushniruk [49] argues that the cognitive processes taking place during clinical decision making can be located along a cognitive continuum, which ranges between intuition and rational analysis. Models of rational-analytical decision-making can be divided into two different approaches, the normative and descriptive approach. The classical normative economic theory assumes complete rationality during decision-making processes using axiomatic models of uncertainty and risk (e.g. probability theory or Bayesian theory) and utility (including multi-attribute utility theory) as illustrated by Expected Utility Theory [50] and Subjective Expected Utility [51]. Here, the rationally best course of action is selected among all available possibilities in order to maximize returns. Theories of rational choice represent, however, an unrealistic model of how decision makers act in real-world settings. It has been shown that there is a substantial non-rational element in people's thinking and behavior along with practical limits to human rationality. These factors are evident in several descriptive theories, exemplified by Prospect Theory [52], Regret Theory [53] as well as Simon's theory of bounded rationality [54]. According to Simon, the limits of human rationality are imposed by the complexity of the world, the incompleteness of human knowledge, the inconsistencies of individual preferences and belief, the conflicts of value among people and groups of people, and the inadequacy of the amount of information people can process/compute. The limits to rationality are not static, but depend on the organizational context in which the decision-making process takes place. In order to cope 
with bounded rationality, clinical decision makers rely on cognitive short-cutting mechanisms or strategies, called heuristics, which allow the clinician to make decisions when facing poor or incomplete information. There is, however, some disadvantages related to the use of heuristics. In some circumstances heuristics lead to systematic errors called biases [55] that influence the process of medical decision making in a way that can lead to undesirable effects in the quality of care.

At the other end of the cognitive continuum proposed by Kushniruk [49], one finds naturalistic or intuitive decision making models. Since the 1980s, a considerable amount of research has been conducted on how people make decisions in real-world complex settings (see for example [56]). One of the most important features of naturalistic decision-making is the explicit attempt to understand how people handle complex tasks and environments. According to Zsambok [57], naturalistic decision making can be defined as "how experienced people working as individuals or groups in dynamic, uncertain, and often fast-paced environments, identify and assess their situation, make decisions, and take actions whose consequences are meaningful to them and to the larger organization in which they operate”. Different decision models that are based on the principles of naturalistic decision making are Recognition-primed Decision Model [56, 57], Image theory [58], the Scenario model [58] and Argument-driven models [59]. Details of these models will not be discussed further in this paper.

Research in healthcare decision making has largely been occupied with the 'decision event', i.e. a particular point in time when a decision maker considers different alternatives and chooses a possible course of action. Apart from the naturalistic decision making field, Kushniruk [49] and Patel et al. [35] has proposed a greater focus on medical problem solving, i.e. the processes that precede the decision event. In essence, this argument is in line with Endsley's model of situation awareness.

Turning our attention to the environmental perspective in Endsley's SA model, we will in the next section discuss the modeling of healthcare processes and workflows.

\subsection{Process modeling within healthcare}

Process modeling in healthcare has previously been applied in the analysis and optimization of pathways, during requirements elicitation for clinical information systems and for general process quality improvement [5, 60-63]. Other approaches, mainly from the human-factors field, have used process models as a tool for building shared understanding within teams (e.g. [64]). The adoption of traditional process modeling in healthcare is challenging in many respects. The challenges can, among other factors, be attributed to $[10,61]$ :

- Interrupt and event driven work, creating the need for dynamic decision making and problem solving.

- Processes that span multiple medical disciplines, involving complex sets of medical procedures.

- Different types of, and often individualized, treatments.

- A large number of possible and unpredictable patient care pathways.

- Many inputs (resources and people) that can be used in different places.

- Frequent changes in technology, clinical procedures and reorganizations.

In addition, there are different levels of interacting processes in healthcare, as in other organizational domains. Lenz et al. [5] made a distinction between site-specific and site-independent organizational processes (e.g. medical order entry, patient dis- 
charge or result reporting) and medical treatment processes (e.g. diagnosis or specific therapeutic procedures). These distinctions are shown in table 2.

Table 1. Categorization of healthcare processes ([5])

\begin{tabular}{lll}
\hline & Organizational processes & Patient treatment processes \\
\hline Site-independent & Generic process patterns & Clinical guidelines \\
Site-specific adaptation & Organization-specific workflows & Medical pathways \\
\hline
\end{tabular}

In a similar manner, Miller et al. [10] identified four nested hierarchical levels of decision making, including 1) unit resource coordination, 2) care coordination, 3) patient care planning and 4) patient care delivery. They conclude that care coordination and decision making involves two distinct 'information spaces': one associated with the coordination of resources (level $1 \& 2$ above) and one with the coordination and administration of patient care (level 3 \&4) ([10], p. 157). These levels are not independent. Miller et al. found a strong association between patient-related goals and team coordination goals, and called for more research regarding the modeling of information flows and conceptual transitions (i.e. coordination activities) across information spaces. In the remainder of this section we will present a few examples of process modeling efforts related to healthcare settings. This is not a comprehensive review, but serves to illustrate of the type of research that has been done in the area.

Fiore et al. suggests that process modeling can be used as a problem-solving tool for cross-functional teams. They argue that process modeling efforts can lead to the construction of a shared understanding of a given problem [64]. Here, the modeling process in itself enables team members to improve a limited understanding of the business process in question. In a similar manner, Aguilar-Savén claims that business process modeling enables a common understanding and analysis of a business process and argues that a process model can provide a comprehensive understanding of a process [65].

In an attempt to investigate how process models can be used to build shared understanding within healthcare teams, Jun et al. identified eight distinct modeling methods and evaluated how healthcare workers perceived the usability and utility of different process modeling notations [66]. Among the modeling methods evaluated were traditional flowcharts, data flow diagrams, communication diagrams, swim-lane activity diagrams and state transition diagrams. The study, that included three different cases in a real-world hospital setting, concluded that healthcare workers considered the usability and utility of traditional flowcharts better than other diagram types. However, the complexity within the healthcare domain indicated that the use of a combination of several diagrams was necessary.

Rojo et al. applied BPMN when describing the anatomic pathology sub-processes in a real-world hospital setting [67]. They formed a multidisciplinary modeling team consisting of software engineers, health care personnel and administrative staff. The project was carried out in six stages: informative meetings, training, process selection, definition of work method, process description and process modeling. They concluded that the modeling effort resulted in an understandable model that easily could be communicated between several stakeholders.

Addressing the problem of aligning healthcare information systems to healthcare processes, Lenz et al. developed a methodology and a tool (Mapdoc), used to model clinical processes [68]. A modified version of UML's Activity Diagram was used to 
support interdisciplinary communication and cultivate a shared understanding of relevant problems and concerns. Here, the focus was to describe the organizational context of the IT application. They found process modeling to be particular useful in projects where organizational redesign was among the goals.

Ramudhin et al. observed that modeling efforts within healthcare often involved the combination of multiple modeling methods or additions to existing methodology [61]. They proposed an approach that involved the development a new modeling framework customized for the healthcare domain, called medBPM. One novel feature of the framework was that all relevant aspects of a process were presented in one single view. The medBPM framework was tested in a pilot project in a US hospital. Preliminary results was encouraging with regard to the framework's ability to describe both "as-is" (descriptive) and "to-be” (prescriptive) processes.

In a recent paper, Fareedi et al. identified roles, tasks, competences and goals related to the ward round process in a healthcare unit [69]. They used a formal approach to implement the modeling results in the form of an ontology using $\mathrm{OWL}^{1}$ and the Protégé $^{2}$ ontology editor. The overall aim was to improve the effectiveness of information systems use in healthcare by using the model to represent information needs of clinical staff. Another point made by the authors was the formal ontology's direct applicability in improving the information flow in the ward round process. An ontological approach was also taken by Fox et.al: in the CREDO project the aim was to use an ontological approach to task and goal modeling in order to support complex treatment plans and care pathways [69].

A common feature all the languages used in these research efforts is that they presuppose a rational decision maker following the relatively simple if-then-else or caseswitch structures leading to a choice between one of several known alternatives. Here, the decision process itself is embedded in the upstream activities/tasks preceding the decision point. The decision point will then simply act as the point in time when a commitment to action was made. This is unproblematic for trivial, structured decision episodes, but falls short of describing the factors influencing an unstructured problem/decision situation like the ones encountered within complex and dynamic healthcare processes.

\section{$4 \quad$ Research Directions}

The objective of our research is to use different conceptualizations and models of situation awareness in combination with models of clinical decision making as a "theoretical lens" for capturing and describing the decision requirements (i.e. knowledge/expertise, goals, resources, and information, communication/coordination needs) related to the perception, comprehension and projection of a situation leading up to a critical decision. The aim is to investigate how we can model these requirements as extensions to conventional process modeling languages (e.g. BPMN) possibly in the form of a discrete decision perspective [20]. The GRAI Grid formalism as described in for instance [18, 70], is of particular interest to investigate further, as it focuses on the decisional aspects of the management of systems. The GRAI grid de-

\footnotetext{
${ }^{1}$ http://www.w3.org/TR/owl-features/

${ }^{2}$ http://protege.stanford.edu
} 
fines decision centres (points where decisions are made) as well as the informational relationships among these decision points.

In our work, the following preliminary research questions have been identified:

- What can the main research results within clinical decision making and situation awareness tell us about how experts adapt to complexity and dynamism, synthesize and interpret information in context for the purpose of decision making in dynamic work environments?

- How can we model the concept of a "situation" and "context" in complex and dynamic healthcare processes characterized by high levels of coordination, communication and information needs?

- Will the use of a separate decision perspective in a process model enhance the knowledge building process [71] and the shared understanding of the decision context among a set of stakeholders?

- Will the use of a separate decision perspective in process models lead to a better understanding of how we can design information system support for decisionmaking tasks in dynamic work environments?

To address these areas one needs to design and evaluate a set of modeling constructs that makes it possible to represent aspects of coordination, communication and decision making in clinical processes. This involves identifying relevant case(s) from a healthcare work environment and collecting data using participant observation and interviews of subjects in their natural work settings that can be used as a basis for further research work.

The development of the modeling constructs can be done using the principles from design science described for instance by Hevner et al. [72] and March et al. [73]. Hevner et al. [72] define design science as an attempt to create artifacts that serve human purposes, as opposed to natural and social sciences, which try to understand reality as is. We intend to develop a set of modeling constructs (i.e. design artifacts) that can describe the decision requirements that form the basis for adequate situation awareness in complex and dynamic healthcare processes. By developing a decision view, it is possible to envision process models that communicate a decision-centric view in addition to the traditional activity-, role- or information-centred views. From the previous discussion on situation awareness and decision making models, we intend to define what conceptual elements should be included in the decision view. Taking into consideration Endsley's model of situation awareness, the concept of a situation is central along with what constitutes timely, relevant information attuned to the decision maker's current (but probably changing) goals. A number of criteria have been defined to characterize and assess the quality of enterprise and process models and modeling languages (see for instance [15]). Hence, the model constructs developed in relation to the previously mentioned decision view must be evaluated with respect to a set of modeling language quality criteria.

\section{Conclusion}

In this paper we have discussed state of the art in modeling of processes and decisions within health care. The paper relates three strands of research: 1) healthcare process modeling, 2) situation awareness and decision-making theories, and 3) decision sup- 
port technologies with the overall aim of improving decision quality within healthcare.

By studying the dynamic decision making process under complex conditions this can lead us to a better understanding of the communication, coordination and information needs of healthcare personnel operating in dynamic and challenging environments. In addition, we propose that the ability to express these insights as one of several modeling perspectives of healthcare process models could prove to be useful for capturing the requirements that must be imposed on information systems support in dynamic work environments.

\section{References}

1. Clancy, T.R., J.A. Effken, and D. Pesut, Applications of complex systems theory in nursing education, research, and practice. Nurs Outlook, 2008. 56(5): p. 248-256 e3.

2. Dahl, Y., I.D. Sørby, and Ø. Nytrø, Context in care--requirements for mobile context-aware patient charts. Stud Health Technol Inform, 2004. 107(Pt 1): p. 597-601.

3. Fawcett, S.E. and M.B. Cooper, Process integration for competitive success: Benchmarking barriers and bridges. Benchmarking: An International Journal, 2001. 8(5): p. 396-412.

4. Recker, J.C., et al., Business process modeling : a comparative analysis. Journal of the Association for Information Systems, 2009. 10(4): p. 333-363.

5. Lenz, R. and M. Reichert, IT Support for Healthcare Processes - Premises, Challenges, Perspectives. Data and Knowledge Engineering, 2007. 61(1): p. 39-58.

6. Fryk, P. and K. Steins, A Modern Process Perspective, Process Mapping and Simulation in Health Care, in IEEE Workshop on Health Care Management (WHCM)2010, IEEE.

7. Bourgeois, L.J., III and K.M. Eisenhardt, Strategic Decision Processes in High Velocity Environments: Four Cases in the Microcomputer Industry. Management Science, 1988. 34(7): p. pp. 816-835.

8. Langley, A., et al., Opening up Decision Making: The View from the Black Stool. Organization Science, 1995. 6(3): p. 260 -279.

9. Nemeth, C.P., The context for improving healthcare team communication, in Improving Healthcare Team Communication, C.P. Nemeth, Editor 2008, Ashgate. p. 2-5.

10. Miller, A., et al., Care Coordination in Intensive Care Units: Communicating Across Information Spaces. Human Factors: The Journal of the Human Factors and Ergonomics Society, 2010. 52(2): p. 147-161.

11. Reader, T.W., R. Flin, and B.H. Cuthbertson, Communication skills and error in the intensive care unit. Current Opinion in Critical Care, 2007. 13(6).

12. Morrow, D., R. North, and C.D. Wickens, Reducing and Mitigating Human Error in Medicine. Reviews of Human Factors and Ergonomics, 2005. 1(1): p. 254-296.

13. Eisenberg, E.M., The social construction of healthcare teams, in Improving Healthcare Team Communication, C.P. Nemeth, Editor 2008, Ashgate. p. 9-20.

14. Gane, C. and T. Sarson, Structured Systems Analysis: Tools and Techniques1979: Prentice Hall.

15. Krogstie, J., Model-Based Development and Evolution of Information Systems: A Quality Approach.2012: Springer.

16. Nysetvold, A.G. and J. Krogstie, Assessing Business Process Modeling Languages Using a Generic Quality Framework, in Advanced Topics in Database Research, Volume 5, K. Siau, Editor 2006, IGI Global. p. 79-93.

17. Krogstie, J. and H. Jørgensen, Interactive Models for Supporting Networked Organisations, in Advanced Information Systems Engineering, A. Persson and J. Stirna, Editors. 2004, Springer Berlin / Heidelberg. p. 307-332.

18. Lillehagen, F. and J. Krogstie, Active Knowledge Modeling of Enterprises2008: Springer.

19. Olle, T.W., et al., Information systems methodologies: a framework for understanding1988: AddisonWesley.

20. Curtis, B., M.I. Kellner, and J. Over, Process modeling. Commun. ACM, 1992. 35(9): p. 75-90.

21. Mili, H., et al., Business process modeling languages: Sorting through the alphabet soup. ACM Comput. Surv., 2010. 43(1): p. 4:1-4:56. 
22. Bubenko Jr, J.A., et al. Facilitating fuzzy to formal requirements modeling. in First International Conference on Requirements Engineering (ICRE94). 1994. Colorado Springs, USA.: IEEE Computer Society Press.

23. Jarke, M., et al. Theories underlying requirements engineering: an overview of NATURE at Genesis. in Proc. RE'93. 1993.

24. Krogstie, J., A.L. Opdahl, and S. Brinkkemper, Conceptual Modelling in Information Systems Engineering2007: Springer. 356.

25. Zachman, J.A., A framework for information systems architecture. IBM Systems Journal, 1987. 26(3): p. 276-291.

26. Petri, C.A., Kommunikation mit Automaten., in Schriften des Rheinisch-Westfalischen Institut fur Instrumentelle Mathematik1962, Bonn University.

27. Davis, A.M., A comparison of techniques for the specification of external system behavior. Commun. ACM, 1988. 31(9): p. 1098-1115.

28. Winograd, T. and F. Flores, Understanding Computers and Cognition: A New Foundation for Design1986: Addison-Wesley.

29. Dourish, P. Re-space-ing place: "place" and "space" ten years on. in ACM Conf. Computer-Supported Cooperative Work CSCW'06. 2006. Banff, Alberta, Canada: ACM.

30. Harrison, S. and P. Dourish. Re-place-ing space: the roles of place and space in collaborative systems. in Proc. CSCW'96. 1996. Boston, Massachusetts, United States: ACM.

31. Endsley, M.R., Toward a Theory of Situation Awareness in Dynamic Systems. Human Factors: The Journal of the Human Factors and Ergonomics Society, 1995.

32. Pew, R.W., The state of Situation Awareness measurement: heading toward the next century, in Situation awareness: analysis and measurement2000, Routledge.

33. Wright, M.C. and M.R. Endsley, Building shared situation awareness in healthcare settings, in Improving Healthcare Team Communication, C.P. Nemeth, Editor 2008, Ashgate. p. 98-114.

34. Endsley, M.R. and D.J. Garland, Situation awareness: analysis and measurement2000: Routledge.

35. Patel, V.L., D.R. Kaufman, and J.F. Arocha, Emerging paradigms of cognition in medical decisionmaking. Journal of Biomedical Informatics, 2002. 35(1): p. 52-75.

36. Gaba, D.M., S.K. Howard, and S.D. Small, Situation Awareness in Anesthesiology. Human Factors: The Journal of the Human Factors and Ergonomics Society, 1995. 37(1): p. 20-31.

37. Singh, H., et al., Exploring situational awareness in diagnostic errors in primary care. BMJ Quality \& Safety, 2011.

38. Jalote-Parmar, A. and P. Badke-Schaub. Situation awareness in medical visualization to support surgical decision making. 2010. New York, NY, USA: ACM.

39. Paturas, J., J. Pelazza, and R. Smith, Establishing a Framework for Synchronizing Critical Decision Making with Information Analysis During a Health/Medical Emergency. Prehospital and Disaster Medicine, 2011. 26(Supplement S1): p. s61-s61.

40. Falzer, P.R., Cognitive schema and naturalistic decision making in evidence-based practices. Journal of Biomedical Informatics, 2004. 37(2): p. 86-98.

41. Vicente, K.J., Cognitive Work Analysis : Toward Safe, Productive, and Healthy Computer-Based Work1999: CRC Press.

42. Churchman, C.W., Challenge to Reason1968: McGraw-Hill Education.

43. Ellingsen, K. and E. Mathisen, Decision making and information. Conjoined twins?, in NOKOBIT Norsk konferanse for organisasjoners bruk av informasjonsteknologi ( ISSN 1892-0748)2011, Tapir Akademisk Forlag.

44. Mintzberg, H., D. Raisinghani, and A. Théorêt, The Structure of "Unstructured" Decision Processes. Administrative Science Quarterly, 1976. 21(2): p. 246-275.

45. Power, D.J., Decision Support Systems: Concepts and Resources for Managers2002, Westport, Connecticut: Quorom Books.

46. Alenljung, B. and A. Persson, Portraying the practice of decision-making in requirements engineering: a case of large scale bespoke development. Requirements Engineering, 2008. 13(4): p. 257-279.

47. Mosier, K.L. and U.M. Fischer, Judgment and Decision Making by Individuals and Teams: Issues, Models, and Applications. Reviews of Human Factors and Ergonomics, 2010. 6(1): p. 198-256.

48. Roy, J., R. Breton, and R. Rousseau, Decision-making models, in Concepts, Models and Tools for Information Fusion2007, Artech House Publishers. p. 392.

49. Kushniruk, A.W., Analysis of complex decision-making processes in health care: cognitive approaches to health informatics. Journal of Biomedical Informatics, 2001. 34(5): p. 365-76.

50. Von Neumann, J. and O. Morgenstern, Theory of games and economic behavior. Vol. 37. 1947: Princeton University Press. 
51. Savage, L.J., Foundations of Statistics1954, New York: Wiley.

52. Kahneman, D. and A. Tversky, Procpect Theory: An analysis of decision under risk. Econometrica, 1979. 47(2): p. 263-291.

53. Loomes, G. and R. Sugden, Regret Theory: An Alternative Theory of Rational Choice Under Uncertainty. The Economic Journal, 1982. 92(368): p. 805-824.

54. Simon, H.A., Rational decision making in business organizations. The American Economic Review, 1979. 69(4): p. 493-513.

55. Gorini, A. and G. Pravettoni, An overview on cognitive aspects implicated in medical decisions. European journal of internal medicine, 2011. 22(6): p. 547-53.

56. Klein, G., Naturalistic decision making. Human Factors, 2008. 50(3): p. 456-460.

57. Zsambok, C.E. and G. Klein, Naturalistic Decision Making (Expertise: Research \& Applications)1997: Psychology Press.

58. Beach, L.R. and T. Connolly, The Psychology of Decision Making: People in Organizations. 2 ed2005: Sage Publications, Inc.

59. Lipshitz, R., Decision making as argument-driven action, in Decision making in action: Models and methods.1993, Ablex Publishing Co.: Norwood, NJ.

60. Becker, J., R. Fischer, and C. Janiesch, Optimizing U.S. Health Care Processes - A Case Study in Business Process Management. AMCIS 2007 Proceedings, 2007.

61. Ramudhin, A., E. Chan, and A. Mokadem. A Framework for the Modelling, Analysis and Optimization of Pathways in Healthcare. 2006.

62. Staccini, P., et al., Modelling health care processes for eliciting user requirements: a way to link a quality paradigm and clinical information system design. Int J Med Inform, 2001. 64(2-3): p. 129-142.

63. Petersen, S.A., G. Bach, and A.B. Svarlein, Patient Care across Health Care Institutions: An Enterprise Modelling Approach, in The Practice of Enterprise Modeling, P. Bommel, et al., Editors. 2010, Springer Berlin Heidelberg. p. 91-105.

64. Fiore, S.M. and J.W. Schooler, Process mapping and shared cognition: Teamwork and the development of shared problem models, in Team cognition: Understanding the factors that drive process and performance2004, American Psychological Association: Washington, DC, US. p. 133152.

65. Aguilar-Savén, R.S., Business process modelling: Review and framework. International Journal of Production Economics, 2004. 90(2): p. 129-149.

66. Jun, G.T., et al., Health Care Process Modelling: Which Method When? International Journal for Quality in Health Care, 2009. 21(3): p. 214-224.

67. Rojo, M.G., et al., Implementation of the Business Process Modelling Notation (BPMN) in the modelling of anatomic pathology processes. Diagnostic Pathology, 2008. 3(Suppl 1): p. S22-S22.

68. Lenz, R. and K.A. Kuhn, Towards a continuous evolution and adaptation of information systems in healthcare. Int J Med Inform, 2004. 73(1): p. 75-89.

69. Ali Fareedi, A. and V. Tarasov, Modelling of the Ward Round Process in a Healthcare Unit, in The Practice of Enterprise Modeling, W. Aalst, et al., Editors. 2011, Springer Berlin Heidelberg: Berlin, Heidelberg. p. 223-237.

70. Ravat, F., Collaborative Decision Making: Perspectives and Challenges2008: Ios Pr Inc.

71. Fiore, S.M., et al., Towards an understanding of macrocognition in teams: developing and defining complex collaborative processes and products. Theoretical Issues in Ergonomics Science, 2010. 11(4): p. 250-271.

72. Hevner, A.R., et al., Design Science in Information Systems Research. MIS Quarterly, 2004. 28(1): p. 75-105.

73. March, S. and G. Smith, Design and Natural Science Research on Information Technology. Decision Support Systems, 1995. 15: p. 251 - 266. 